\title{
Permainan Warna Berpengaruh Terhadap Kreativitas Anak Usia Dini
}

\author{
Aisyah $^{凶}$ \\ Program Studi PG-PAUD Universitas PGRI Adi Buana Surabaya
}

\begin{abstract}
Abstrak
Dunia penuh dengan warna dan anak-anak sangat menyukai warna-warna yang cerah. Ketika memasuki usia pra sekolah, saat mewarnai gambar juga menggunakan warna-warna yang cerah seperti merah, kuning, biru, atau warna-warna pelangi (mejikuhibiniu). Padahal di dunia ini tidak hanya awarna tersebut, tetapi ratusan bahkan bisa ribuan warna. Sehingga ketika anak mewarnai gambar (misalnya dengan krayon yang berjumlah 12 warna) yang terlihat hanya sebatas warna yang ada. Mereka kurang tahu atau bahkan mungkin belum tahun bahwa dari ke-12 warna yang ada dapat memperoleh warna-warna lain yang baru. Penelitian ini bertujuan untuk membuktikan bahwa permainan warna yang diberikan kepada siswa Taman Kanak-Kanak dapat meningkatkan kreativitas anak dalam mewarnai gambar. Manfaat penelitian diharapkan dapat memberi sumbangan dalam rangka pemahaman adanya kegiatan permainan warna dalam meningkatkan kreativitas anak. Pengumpulan data dilakukan dengan teknik check list dan observasi, dan diolah dengan car anon statistik atau bisa juga disebut dengan teknik analisis sederhana dengan mencari presentase. Hasil penelitian menunjukkan bahwa permainan warna signifikan dalam mempenagruhi kreativitas anak.
\end{abstract}

Kata Kunci : Permainan Warna, Kreativitas, Anak Usia Dini

\begin{abstract}
The world is full of colors, and the kids love the bright colors. When pre-school age, they also like to use bright colors like red, yellow, blue, or rainbow colors (mejikuhibiniu). Though in this world there are not only these colors, but hundreds or thousands of colors. So when they use crayons that amount to 12 colors, that look only limited to existing colors. They know less or may not even know that from the 12 existing colors they can get other new colors. This study aims to prove that the color game given to Kindergarten students can improve the creativity of children in coloring the image. Early. The benefits of this research is expected to contribute in order to understand the existence of color game activities in improving the creativity of children Early Age. Data collection by check list and observation techniques, and processed in a nonstatistik way or can also be referred to as a simple statistical analysis by finding percentages. The results show that color games are significant to influencing the creativity of young children.
\end{abstract}

Keywords: Color Games, Creativity, Early Childhood

@ Jurnal Obsesi Prodi PG-PAUD FIP UPTT 2017

$\triangle$ Corresponding author:

Address : Sumbersari, Jember, Indonesia

ISSN 2356-1327 (Media Cetak)

Email : aisyah@unipasby.ac.id

ISSN 2549-8959 (Media Online) 


\section{PENDAHULUAN}

Dunia penuh dengan warna, dan anak-anak sangat menyukai warna- warna. Apalagi warna-warna yang sangat cerah. Dalam memilih baju, makanan, bahkan mainanpun mereka lebih suka atau cenderung memilih warna-warna yang sangat cerah dan mencolok.

Ketika mereka memasuki usia pra sekolah, saat mewarnai gambar mereka juga suka menggunakan warna-warna yang cerah seperti merah, kuning, biru, atau warna-warna pelangi (mejikuhibiniu). Padahal di dunia ini tidak hanya terdapat warna tersebut, tetapi ratusan bahkan mungkin bisa ribuan warna. Pada akhirnya ketika mereka mewarnai gambar (misalnya dengan krayon yang berjumlah 12 warna) yang terlihat hanya sebatas warna yang ada. Mereka kurang tahu atau bahkan mungkin belum tahu bahwa dari ke-12 warna yang ada mereka bisa mendapatkan warna-warna lain yang baru.

Dari kenyataan yang ada tersebut di atas, maka penulis ingin mengajak anakanak untuk mengenal macam-macam warna lebih banyak lagi melalui permainan warna supaya mereka bisa berkreativitas dan berani mencampur warna-warna yang sudah ada untuk membuat warna-warna lain yang baru. Apabila keterampilan mencampur warna sudah di dapat, diharapkan pada saat mewarnai mereka sudah lebih kreatif lagi dalam mewarnai gambar. Dalam proses belajar nanti rencananya penulis akan mengajarkan anak-anak tentang warna melalui permainan warna.

Hal ini dikarenakan sebagian besar waktu yang dimiliki anak-anak terutama anak usia dini yaitu berinteraksi dengan sebaya mereka untuk bermain,karena dunia anak adalah dunia bermain. Karena bermainan adalah aktivitas yang menyenangkan bagi anak usia dini.

Menurut Gordon \& Browne pada tahun 1985, mengatakan bahwa "Bila anak TK diberi kesempatan untuk mengekspresikan diri secara kreatif maka hal ini akan menimbulkan gairah untuk belajar." (R.Moeslichatoen, 2004:12). Bagi anak, mewarna adalah kegiatan yang sangat disukai dan mengasyikkan. Saat anak-anak mewarna gambar, imajinasi dan kreativitas mereka berkembang. Apalagi bila mereka diberi gambar-gambar pilihan dengan penyajian yang menarik. Imajinasi dan kreativitas anak-anak akan lebih terangsang. Oleh karena itu, kegiatan mewarna sangat baik untuk perkembangan kemampuan daya cipta atau kreativitas anak.

Anak dan permainan merupakan dua pengertian yang hampir tidak dapat dipisahkan satu sama lain. Berpikir mengenai anak selalu menimbulkan asosiasi mengenai bermain. (F.J.Monks, A.M.P.Knoers, Siti Rahayu Haditono, 2006:131)

"Dunia anak adalah dunia bermain. Oleh karena itu, dalam mendidik pun semua masih melalui bermain, baik itu sarana maupun prasarana. Usia 5 tahun pertama yang disebut sebagai golden age (usia emas), akan sangat menentukan bagi seorang anak. Pada usia ini, aspek kognitif, fisik, motorik, dan psikososial anak berkembang secara pesat. Oleh karena itu, diperlukan stimulasi-stimulasi yang mampu mengoptimalkan seluruh aspek tersebut agar seorang anak mampu menjadi pribadi yang matang, bertanggung jawab, dan mampu menghadapi segala permasalahan dalam hidupnya. Salah satu cara mengoptimalkan kemampuan kognitif, fisik, dan psikososial seorang anak adalah dengan menstimulasinya. Salah satu alat atau sarana mestimulasinya adalah dengan mainan atau permainan" (Maimunah Hasan,2010:271-272).

Permainan dan bermain memiliki arti dan makna tersendiri bagi anak. Permainan mempunyai arti sebagai sarana mensosialisasikan diri (anak) artinya permainan digunakan sebagai sarana membawa anak ke dalam masyarakat. Permainan sebagai sarana untuk mengukur kemampuan dan potensi diri anak. Anak akan menguasai berbagai macam benda, memahami sifat-sifatnya maupun peristiwa yang berlangsung di dalam lingkungannya. (Diana Mutiah, 2010:113). 
Penelitian mengenai permainan pada anak-anak membuktikan bahwa permainan dapat memajukan aspek-aspek perkembangan seperti motorik, kreativitas, kecakapan-kecakapan sosial dan kognitif dan juga perkembangan motivasional dan emosional. (F.J. Monks - A.M.P. Knoers, Siti Rahayu Haditono, 2006:141).

Beberapa permainan warna yang dapat dipakai untuk belajar mengenal warna antara lain (Harsini, 2006:23-26) mencampur dua warna primer menjadi warna baru (merah+kuning=oranye, merah+biru=ungu, kuning+biru=hijau) dan mewarna dengan cara cetak lipatan menggunakan cat air, caranya yaitu melipat kertas menjadi dua, kemudian mencampurkan warna cat air yang disukai, dilanjutkan dengan membuat satu lipatan diberi cat air, dan yang terakhir melipatkertas sambil ditekan, kemudian buka lipatannya.

Cara mewarnai dengan cara cetak benang menggunakan cat aircaranya: yaitu melipat kertas menjadi dua, kemudian mencelup benang ke dalam cat air, dilanjutkan dengan meletakkan benang di atas kertas, kemudian melipat kertas sambil sedikit ditekan, dan menarik benang kemudian membuka lipatan kertas.

Mewarna dengan cara mencetak dengan bahan alam, caranya yaitu mengeluarkan cat air ke tempat cat air, masukkan/celupkan potongan bahan alam (pelepah pisang) ke dalam cat air, meletakkan potongan pelepah pisang di kertas/distempelkan. Bentuk cetakan dengan membuat pola bunga.

Cara mewarnai dengan menggunakan jari (finger painting), caranya yaitu membuat bentuk bulat dari cetakan ibu jarimu, membuat lebih banyak lagi cetakan jari. Tambahkan tangkai warna hijau.

Cara mewarnai dengan cara ditiup menggunakan sedotan, caranya yaitu mengeluarkan cat air ke tempat cat air, meneteskan beberapa warna cat air tadi ke atas kertas, dan meniup tetesan cat air tadi menggunakan sedotan ke sembarang arah.
Kreativitas (creativity) adalah salah satu kemampuan intelektual manusia yang sangat penting, dan oleh kebanyakan ahli psikologi kognitif dimasukkan ke dalam kemampuan memecahkan masalah. Kreativitas juga sering disebut berpikir kreatif (creative thinking). Di bidang lain misalnya manajemen dan teknologi, kreativitas sering disebut berpikir inovatif (innovative thinking). Semua istilah ini berkaitan dengan usaha menemukan, menghasilkan atau menciptakan hal-hal baru.

Kreativitas dapat didefenisikan sebagai aktivitas kognitif atau proses berpikir untuk menghasilkan gagasangagasan yang baru dan berguna atau new ideas and useful (Halpern, 1996; Suharnan, 1998, 2000a), (dalam Suharnan, 2005:373$375)$.

Sikap orang tua tidak permisif atau otoriter, pemberian pengetahuan yang banyak. (Pustaka Familia,2010:255). Secara umum, Amabile (dalam Reni Akbar Hawadi, 2004:115-116) menyebutkan beberapa upaya yang bisa digunakan untuk perkembangan kreativitas anak yaitu Kebebasan, artinya tidak selalu berusaha mengendalikan anak-anaknya dan tidak merasa cemas dengan apa yang dilakukan oleh anak; rasa hormat, artinya menghargai dan menghormati keberadaan anak sebagai individu yang unik dan memiliki kemampuan secukupnya; kedekatan emosional secukupnya, artinya pendidikan tidak bersikap posesif yang menyebabkan anak tergantung pada orang lain; nilaidan bukan peraturan, artinya tidak menjejali anak dengan peraturan-peraturan yang detail; prestasidan bukan angka, artinya lebih menekankan pentingnya meraih halhal sebaik mungkin dengan tidak menekan anak untuk memeroleh angka yang baik di rapor; orang tua aktif, orang tua memiliki minat yang beragam baik yang di dalam maupun di luar rumah dan tidak menekankan pada perbedaan status sosial serta tidak terpengaruh oleh tuntutan sosial; menghargai kreativitas, yaitu mendukung anak untuk melakukan hal-hal yang kreatif melalui peralatan dan pengalaman baru yang menarik maupun dengan pemberian 
les; visi, orang tua perlu mempunyai visi yang jekas tentang anaknya bahwa mereka mampu untuk melakukan hal-hal yang luar biasa, yang kreatif sesuai dengan bakat serta keterampilan yang dimilikinya.

Di samping delapan saran di atas, Amabile (dalam Reni Akbar Hawadi, 2004:116) menekankan bahwa sebaiknya anak-anak perlu banyak menghabiskan waktunya untuk bermain. Hal ini sesuai dengan hasil penelitiannya bahwa anak yang kreatif adalah anak yang banyak menghabiskan waktunya dengan bermain. Di rumah, Amabile memberikan saran agar dikembangkan kebiasaan-kebiasaan kreatif pada anak, yaitu: mempertanyakan apa yang dilihat; menemukan cakrawala baru dalam menjalani persoalan; menemukan cara baru untuk melakukan apapun; mencipta sesering mungkin.

Untuk itu sikap orang tua yang diharapkan anak antara lain membuat anak berani untuk mencoba dan maju; hangat dan memberi semangat; menikmati suasana disekitarnya; sering berada dekat anak; memuji anak; mampu bekerja sama; mendorong anak untuk mandiri.

Dengan demikian aktivitas anak usia dini yang suka bermain merupakan suatu kegiatan yang dapat mengembangkan kretivitas yang ada dalam diri setiap anak, begitu juga dengan aktivitas bermain warna akan sangat berpengaruh untuk menggali kreativitasnya dalam kegiatan mewarnai sebuah gambar atau media yang membutuhkan pewarnaan.

\section{METODE PENELITIAN}

Penelitian yang akan dilaksanakan ini adalah penelitian kuantitatif eksperimen melalui metode pemberian tugas Dengan mengunakan metode pemberian tugas merupakan tugas atau pekerjaan yang sengaja diberikan kepada anak yang harus dilaksanakan dengan baik. Tugas tersebut diberikan kepada anak untuk memberi kesempatan kepada mereka untuk menyelesaikan tugas yang didasarkan pada petunjuk langsung dari guru yang sudah dipersiapkan sehingga anak dapat menjalani secara nyata dan melaksanakan dari awal sampai tuntas.
Tugas yang diberikan kepada anak dapat diberikan secara perseorangan atau kelompok. (Moeslichatoen, 2004:181) Dengan demikian untuk lebih jelasnya lihat Bagan 1 kerangka penelitian di bawah:

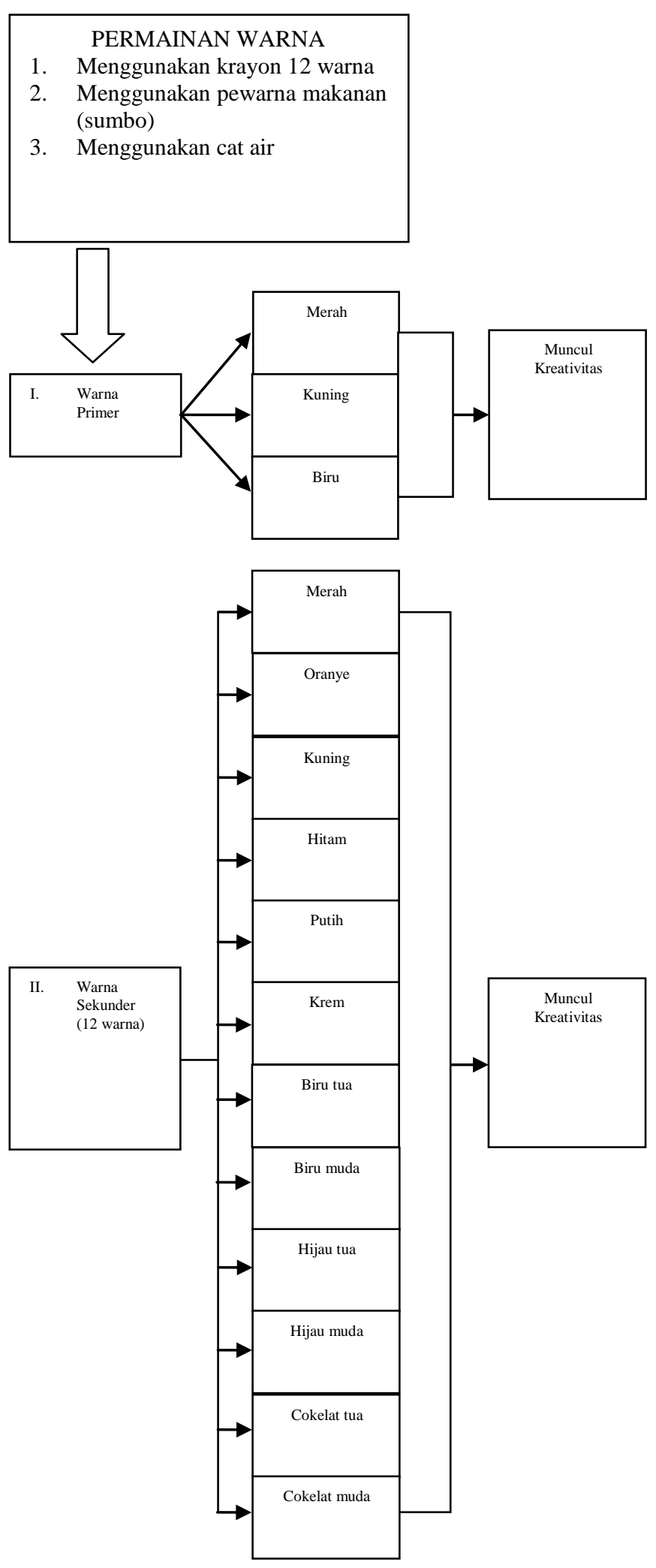

Bagan 1. Kerangka Penelitian 
Pengumpulan data dilakukan melalui teknik check list (daftar catatan) dan teknik observasi.Menurut Cholid Narbuko dan H. Abu Achmadi, (2005:74):"“Check list yaitu suatu daftar yang berisi nama-nama subjek dan faktorfaktor yang hendak diselidiki, yang bermaksud mensistematiskan catatan observasi, alat ini lebih memungkinkan peneliti memeroleh data yang meyakinkan di bidang yang lain. Sebab faktor-faktor yang akan diteliti sudah dicatat dalam daftar isian, penelitian tinggal memberikan tanda (check) pada blangko itu untuk tiap subjek yang diobservasi."

Husaini Usman dan Purnomo Setiady Akbar, (2004:54-57) mengatakan "Observasi ialah pengamatan dan pencatatan yang sistematis terhadap gejalagejala yang diteliti. Observasi menjadi salah satu teknik pengumpulan data apabila: sesuai dengan tujuan penelitian; direncanakan dan dicatat secara sistematis, dandapat dikontrol keandalannya (reliabilitasnya) dan kesahiannya (validitasnya)."

Pengumpulan data dilakukan untuk menilai pengembangan kreativitas anak dalam melakukan pencampuran warna (gradasi warna).

\section{HASIL DAN PEMBAHASAN}

Hasil analisis data skor dapat dilihat pada tabel1 dibawah ini

Tabel 1 Data Rekap Pre Test dan Post Test

\begin{tabular}{|l|l|l|l|l|}
\hline & \multicolumn{2}{|c|}{ Pre test } & \multicolumn{2}{c|}{ Post test } \\
\hline & Kreatif & $\begin{array}{c}\text { Sangat } \\
\text { Tidak } \\
\text { Kreatif }\end{array}$ & Kreatif & $\begin{array}{c}\text { Sangat } \\
\text { Tidak } \\
\text { Kreatif }\end{array}$ \\
\hline Jumlah & 1 & 18 & 24 & 3 \\
\hline $\begin{array}{l}\text { Persen- } \\
\text { tase }\end{array}$ & $2,56 \%$ & $46,15 \%$ & $61,5 \%$ & $7,69 \%$ \\
\hline
\end{tabular}

Secara lebih rinci, data pre tes dan post tes dapat dilihat pada tabel 2 (lampiran).

Berdasarkan hasil analisis data yang sudah diperoleh dan telah diolah oleh penulis maka, dapat diketahui bahwa kegiatan permainan warna dapat meningkatkan kreativitas anak. Hasil penelitian menunjukkan bahwa anak-anak begitu bergairah dan bersemangat saat melakukan berbagai kegiatan permainan warna sehingga dari satu anak yang muncul tergolong kreatif saat pre test (sebelum kegiatan permainan warna) dapat meningkat menjadi dua puluh empat anak yang muncul tergolong kreatif sesudah terjadi kegiatan permainan warna (saat post test).

Sedangkan dari delapan belas anak yang muncul tergolong sangat tidak kreatif saat pre test (sebelum kegiatan permainan warna) dapat menurun hanya menjadi tiga anak yang muncul tergolong sangat tidak kreatif sesudah terjadi kegiatan permainan warna (saat post test).

\section{KESIMPULAN}

Berdasarkan hasil analisa data teknik permainan warna dapat meningkatkan kreativitas anak setelah mereka diberi kegiatan bermainan warna. Hal ini dapat diketahui dari satu anak yang muncul tergolong kreatif saat pre test (sebelum kegiatan permainan warna) dapat meningkat menjadi dua puluh empat anak yang muncul tergolong kreatif sesudah terjadi kegiatan permainan warna (saat post test).

\section{DAFTAR PUSTAKA}

Aisyah, Siti. dkk.(2010). Perkembangan dan Konsep Dasar Pengembangan Anak Usia Dini. Jakarta: Universitas Terbuka.

Arikunto, Suharsimi. (2006). Prosedur Penelitian Suatu Pendekatan Praktik. Jakarta: Rineka Cipta.

Astuti, A. (2016). Peningkatakan Kemampuan Anak Mengenal Konsep Bilangan Melalui Permainan Kartu Angka di Kelompok B TK Aisyiyah Pulau Payung Kecamatan Rumbio Jaya.Jurnal Obsesi : Journal Of Early Childhood Education, 2(1), 90-99

Fauziddin, M. (2014). Pembelajaran PAUD, Bermain, Cerita, dan Menyanyi Secara Islami. 
Harsini. (2006). Kerajinan Tangan dan Kesenian Sekolah Dasar Kelas 1. Jakarta: Widya Utama.

Hasan, Maimunah. (2009). Pendidikan Anak Usia Dini. Yogyakarta: Diva Press.

Hawadi, Reni Akbar. (2004). Psikologi Perkembangan Mengenal Sifat, Bakat, dan Kemampuan Anak. Jakarta: Grasindo.

Maskur. (2008). Pendidikan Anak Usia Dina Makalah. Tersedia pada pakdesofa.blog.plasa.com/archeves/ date/2008/07/page/2-39. Diakses pada 1 Pebruari 2009.

Moeslichatoen. (2004). Metode Pengajaran di Taman Kanak-Kanak. Jakarta: Rineka Cipta.

Monks, F.J., Knoers, A.M.P., Haditono, Siti Rahayu. (2006). Psikologi Perkembangan Pengantar Dalam Berbagai Bagiannya. Yogyakarta: Gajah Mada University Press.

Mutiah, Diana. (2010). Psikologi Bermain Anak Usia Dini. Jakarta: Kencana Prenada Media. 